\title{
ANALISIS PERANCANGAN BUSUR PANAH POLYVYNIL CHLORIDE TIPE RECURVE DI ISI BAMBU DAN RESIN EPOKSI
}

\author{
Muhammad Dzulfikar* dan Nahar. \\ Jurusan Teknik Mesin, Fakultas Teknik, Universitas Wahid Hasyim \\ Jl. Menoreh Tengah X/22, Sampangan, Semarang 50236. \\ "Email: muhammaddzulfikar@unwahas.ac.id
}

\begin{abstract}
Abstrak
Dalam bidang olahraga tertentu material tradisional tetap bertahan dan hanya sedikit mengalami perubahan material. Topik-topik yang dibahas mencakup teknik percetakanpolimer yang revolusioner. Busur panah mengalami berbagai macam perkembangan. Maka perancangan yang akan diteliti sedikit berbeda dengan menggunakan PVC sebagai bahan material utamanya sedangkan resin dan bambu sebagai pelengkap. Adapun perancangan tersebut, dengan memipihkan PVC. Kemudian dilakukan tiller atau bending dan menimbang busur panah untuk mengetahui bow weight, draw weight dan draw length pada busur panah pada yang memenuhi standard panahan. Nilainya bow weightnya 24,44 lbs, 34,16 lbs, 29,11 lbs, 19,59 lbs . Sementara nilai draw length sepanjang 25,6 inchi, 26,2 inchi , 26,8 inchi, 26,6 inchi. Nilai draw weightnya 26,89 lbs, 32,02 lbs, 37,57 lbs, 21,54 lbs.
\end{abstract}

Kata kunci: bow, busur panah, pvc, resin, bambu.

\section{PENDAHULUAN}

Sebuah dunia teknik dan perekayasaan banyak merambah berbagai bidang. Dalam bidang olahraga tertentu material tradisional tetap bertahan dan hanya sedikit mengalami perubahan material, topik-topik yang dibahas mencakup teknik percetakan-polimer yang revolusioner (raket tenis), kekakuan dan kelenturan lengkung (stik golf), penyimpanan dan transfer energi (busur panah), masalah penyambungan (rangka sepeda), kompositkomposit baja dupleks (bilah anggar), ketahanan pada temperatur rendah (pengikat papan luncur salju) dan absorpi kejut (helm pengaman). Kombinasi yang vital antara struktur dan sifat akan terlihat sangat jelas. Terlihat bahwa sukses komersil selalu menuntut kemampuan untuk mengindentifikasi secara presisi sifat-sifat material yang penting selama proses desain dan pengembangan. (R. E. Smallman,R. J. Bishop, 1999)

Dalam penelusuran penulis di search engine sangat jarang meneliti proses pembuatan busur panah PVC. Namun jika mencari tempat penjualan busur panah PVC, kreativitas SDM di Indonesia tak kalah jauh dari internasional.

Namun ada literasi yang hampir mendekati dari penelitian ini, World Archery South Africa dan yang jadi acuan dalam proses pembuatan. Begitu pula buku The Impossible Bow: Building Archery Bows With PVC Pipe,karya Nicholas Tomihama, mengenai proses pembuatan busur panah PVC.
Berbekal informasi diatas penulis mencoba merancang ulang dengan bahan yang mudah didapat di Indonesia. Komposit sebagai dasar utama penelitian ini, dengan campuran PVC, Bambu, dan resin epoksi.

Dan berdasarkan hal - hal tersebut diatas maka penulis mencoba untuk mengadakan suatu penelitian dengan judul :

"Perancangan Busur Panah Pvc (Polyvynil Chloride) Tipe Recurve Dengan Variasi Bambu Dan Resin Epoksi"

\section{Kajian Pustaka \\ Busur panah}

Busur panah terdiri atas 3 jenis dasar sebagai berikut (Johnson, 2014):

Longbow: Busur Longbow biasanya terbuat dari material kayu tunggal. Busur Recurve: Serupa dengan gaya tembak busur di Olimpiade, tipe busur recurve bahwa limb memanjang, ketika digantung, kurva mundur dekat riser dan kemudian kurva ke depan (recurve) di ujung. Busur ini memiliki tarikan dan lepasan dari pada busur Longbow.Busur Compound: Lebih pendek dan lebih kompak, busur yang awalnya diciptakan untuk berburu tetapi sekarang sangat populer di kalangan para pemanah kompetitif. Jenis ini memiliki serangkaian roda, cams, kabel, dan string. Cam adalah jenis khusus roda yang menciptakan kecepatan busur yang lebih besar daripada roda bulat. 


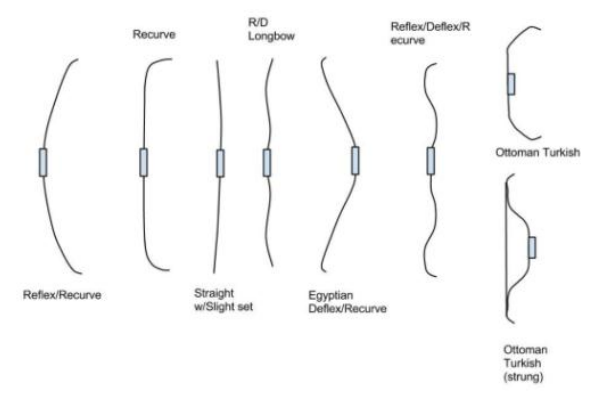

\section{Gambar 1 Tipe-tipe desain Busur panah (Anonim)}

\section{Risers}

Riser adalah "inti" dari bentuk busur. Sampai baru-baru ini, riser terbuat dari kayu, sering dikombinasikan dari berbagai jenis kayu. Tapi muncul bahan modern (panah karbon, Fast Flight strings) berarti bahwa kayu riser tidak bisa mengatasi ketegangan ditempatkan pada mereka dan perkembangan riser ditangani logam-sejak telah berlangsung. (Johnson, 2014)

\section{Limbs}

Limb bisa disebut bagian paling penting dari busur panah. Paling pokok dari limb ialah mengiramakan gerakan panah. Setiap memutar, atau akhiran antara limb selama proses itu dan itu akan sangat sulit untuk menempatkan panah pada ring 10 .

\section{Strings}

Pastikan panjang string yang benar saat digunakan. Biasanya ini dibeli dengan panjang untuk mencocokkan panjang busur. Dengan menggunakan string yang benar ini memastikan jumlah yang tepat dari string berada di sekitar recurve pada setiap limb dan tinggi brace adalah spesifikasi produsen. Periksa buku pegangan busur untuk memastikan tinggi brace yang direkomendasikan untuk panjang busur diberikan.

Yang dibutuhkan adalah standardisasi unit, dimensi, rumus, dan metode pengukuran.

$\mathrm{F}=\mathrm{F}_{\mathrm{o}} *\left(\mathrm{~L}_{\mathrm{o}} / \mathrm{L}\right)^{3} *\left(\mathrm{~W} / \mathrm{W}_{\mathrm{o}}\right) *\left(\mathrm{~T} / \mathrm{T}_{\mathrm{o}}\right)^{3}$

Diketahui:

$\mathrm{F}=$ draw length yang tak diketahui

$\mathrm{L}=$ panjang busur yang dihitung antar string nocks

$\mathrm{W}=$ kedalaman bendinglimb busur pada point di tengah
$\mathrm{T}=$ tebal menutup ke transisi kasan/sal transition (tempat tertipis limb)

$\mathrm{F}_{\mathrm{o}}, \mathrm{L}_{\mathrm{o}} \mathrm{W}_{\mathrm{o}}$ and $\mathrm{T}_{\mathrm{o}}$ simbol perhitungan busur yang diketahui draw lengthnya (Karpowicz, 2008)

\section{Resin Epoksi}

Resin epoksi dapat didefinisikan sebagai setiap molekul yang mengandung dua atau lebih kelompok alphaepoksi yang dapat direaksikan untuk membentuk sistem termoset. Sebuah contoh dari resin epoksi difungsi adalah diglycidyl ether of Bisphenol-A (DGEBA) yang dibentuk oleh reaksi Bisphenol-A dengan epiklorohidrin di hadapan natrium hidroksida. Resin ini mempunyai karakteristik keras dan getas, tetapi dalam penggunaan, plastik hampir selalu mengandung bahan campuran lain untuk menyesuaikan sifat mekaniknya, baik dari sisi kekuatan, kekenyalan, keuletan, dll.

\section{Bambu}

Bambu adalah tanaman jenis rumputrumputan dengan rongga dan ruas di batangnya. Bambu memiliki banyak tipe. Nama lain dari bambu adalah buluh, aur, dan eru. Di dunia ini bambu merupakan salah satu tanaman dengan pertumbuhan paling cepat. Karena memiliki sistem rhizoma-dependen unik, dalam sehari bambu dapat tumbuh sepanjang $60 \mathrm{~cm}(24$ inchi) bahkan lebih, tergantung pada kondisi tanah dan klimatologi tempat ia ditanam. Bambu mampu menolak lebih tarik daripada kompresi. Slim tabung adalah Superior kesempatan ini, terlalu. Di dalam kulit luar silificated Anda menemukan beban aksial ekstrem - elastik paralel serat dengan kekuatan tarik $40 \mathrm{kN} / \mathrm{cm}^{2}$. Sebagai perbandingan: serat kayu ekstrem yang kuat dapat menolak ketegangan hingga $5 \mathrm{kN} / \mathrm{cm}^{2}$ dan baja ST 37 dapat menolak ketegangan tertinggi mungkin dari $37 \mathrm{kN} / \mathrm{cm}^{2}$.

\section{METODOLOGI PENELITIAN \\ Bahan dan Alat \\ Bahan Penelitian}

Untuk kelancaran penelitian diperlukan beberapa bahan yang digunakan untuk mencapai maksud dan tujuan penelitian. Adapun bahan dan alat yang digunakan adalah sebagai berikut:

\section{Pipa PVC}

Pipa Pvc yang digunakan sebagai limbs.

Pipa PVC tersebut menggunakan ukuran 3/4 
inchi sesuai dengan ukuran standar internasional busur panah diatas.

\section{Bambu}

Bambu digunakan sebagai isian pada limb di PVC. Ada dua cara untuk mengisi bambu yang digunakan : dipotong tipis hingga $0.5 \mathrm{~mm}$ dan dipotong menyerupai sumpit.

\section{Resin Epoxy}

Selain sebagai pengikat matriks bambu, resin digunakan sebagai lem untuk memudahkan mengikatkan bambu.

\section{Kayu Mahoni}

Kayu ini digunakan untuk pembuatan riser atau handle busur panah

\section{Alat Penelitian}

Alat-alat dalam proses perancangan busur panah sebagai berikut:

\section{Limb}

Limb yang akan dibuat menggunakan pipa pvc. Adapun alat penunjang lain:

a) Cetakan untuk memipihkan pvc berupa dua kayu dengan lebar $6 \mathrm{~cm}$ dan panjang satu meter.

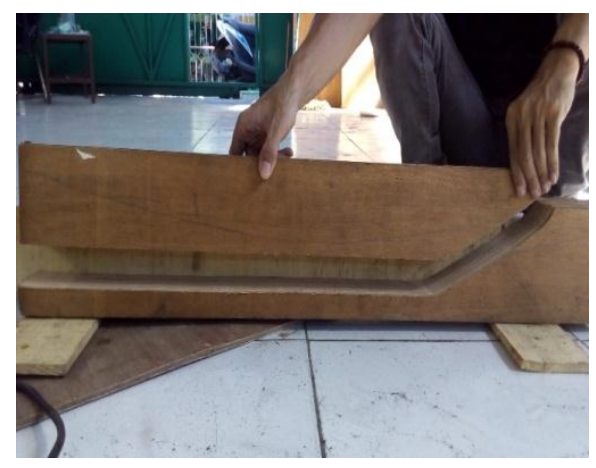

Gambar 2 Cetakan limb dari kayu

b) Hotgun.

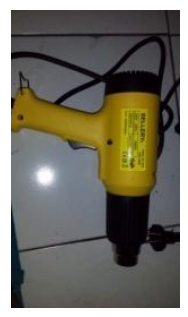

\section{Gambar 3 Hotgun}

c) Clamp3 inchi

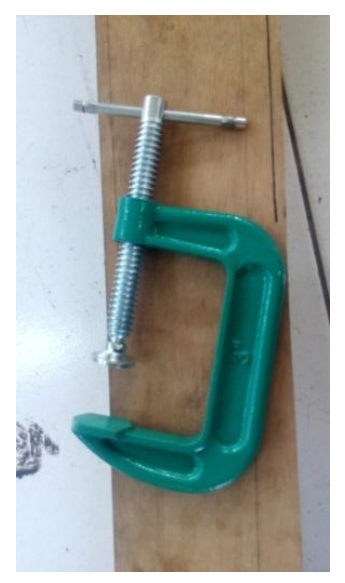

\section{Gambar 4 Klem 3 inchi}

d) Alat ukur : timbangan digital, penggaris

e) Alat potong : pvc bender, gergaji; kayu dan besi,

f) Ampelas

g) Riser

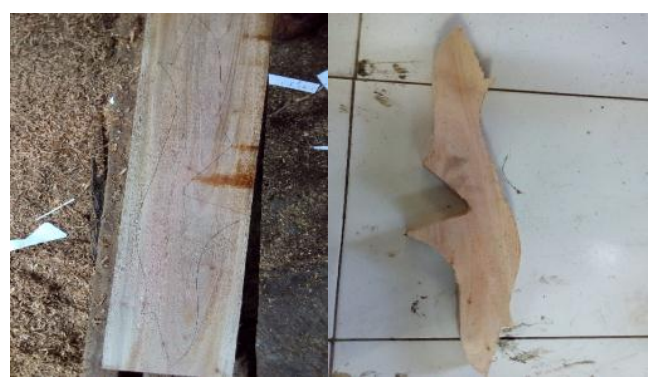

\section{Gambar 5 Desain riser dan hasil jadi riser}

2. Riser ini dibuat dari kayu mahoni. Adapun alat-alat yang digunakan :

a) Gergaji

b) Alat ukur

c) Pensil dan kertas untuk sketsa desain riser

3. String

String yang digunakan menggunakan benang poliester 20/6

\section{Alat Pengujian}

a) Alat uji bending

b) Tiller atau mengukur menggunakan kayu

c) Ukur dan timbang kelenturan menggunakan timbangan digital

Sebelum membuat busur panah pvc perlu dilakukan pemilihan. Hal ini perlu dilakukan karena tipe dan spesifikasi PVC dari tiga merk berbeda. Penulis menggunakan beberapa merk sebagai bandingan. Adapun penggunaan untuk limb busur panah tersebut menggunakan 3/4 inchi. 


\section{Prosedur Penelitian}

Desain gambar yang telah digambar oleh Brandon Buscher:

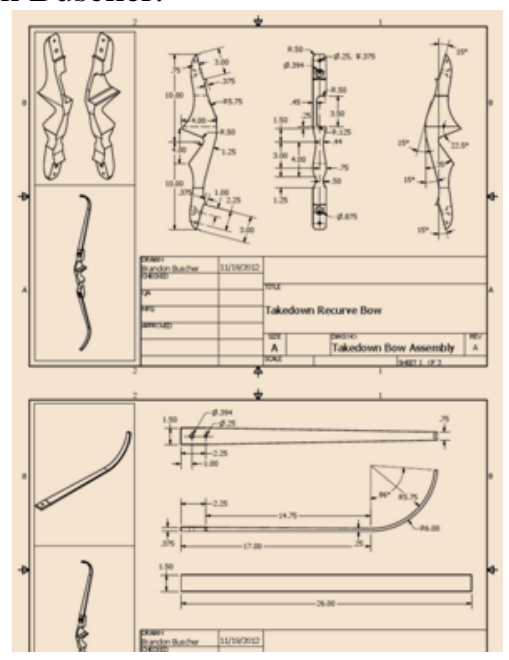

Gambar 6. Desain busur recurve standard (Brandon Buscher, 2012)

\section{Variabel Penelitian}

1. Variabel bebas

a) $\quad \mathrm{PVC} \mathrm{AW} 3 / 4$ inchi merk; Maspion, Boss dan Langgeng

b) Isian Bambu; berbentuk pipih dan sumpit

c) Isian resin epoksi + hardener dan bambu

2. Variabel terikat

a) Draw weight

Draw weight mengacu ASTM F 1544 - 04, busur dengan gaya tarik yang dapat disetel, mengatur puncak atau daya tarik maksimum.

b) Bow weight

Untuk bow weight mengacu pada Archery Manufacturers Organization.

c) Draw Length

Mengacu pada Archery Manufacturers Organization sebagai berikut: panjang tarikan adalah jarak yang ditentukan, atau jarak pada tarikan penuh pemanah, dari titik nocking pada tali mengarah ke titik pivot pegangan busur.

\section{HASIL DAN PEMBAHASAN}

Produk yang dihasilkan ada beberapa macam:

1. Busur panah recurve dengan panjang limb menggunakan PVC masing-masing 23.62 inchi yang diisi bambu dengan tebal $1 \mathrm{~cm}$, panjang riser 15.75 inchi, dan string 49,21 inchi.
Tabel 1 Perhitungan spesimen satu

\begin{tabular}{ccc}
\hline $\begin{array}{c}\text { Bow } \\
\text { Weight } \\
\text { (lbs) }\end{array}$ & $\begin{array}{c}\text { Draw } \\
\text { Length } \\
\text { (inchi) }\end{array}$ & $\begin{array}{c}\text { Draw Weight } \\
\text { (lbs) }\end{array}$ \\
\hline 24,87 & 25.6 & 27.357 \\
24,67 & 25.6 & 27.137 \\
24,76 & 25.6 & 27.236 \\
24,57 & 25.6 & 27.027 \\
24,89 & 25.6 & 27.379 \\
24,08 & 25.6 & 26.488 \\
23,99 & 25.6 & 26.389 \\
24,49 & 25.6 & 26.939 \\
23,89 & 25.6 & 26.279 \\
24,79 & 25.6 & 27.269 \\
24,57 & 25.6 & 27.027 \\
25 & 25.6 & 27.5 \\
23,98 & 25.6 & 26.378 \\
24,03 & 25.6 & 26.433 \\
24,09 & 25.6 & 26.499 \\
\hline
\end{tabular}

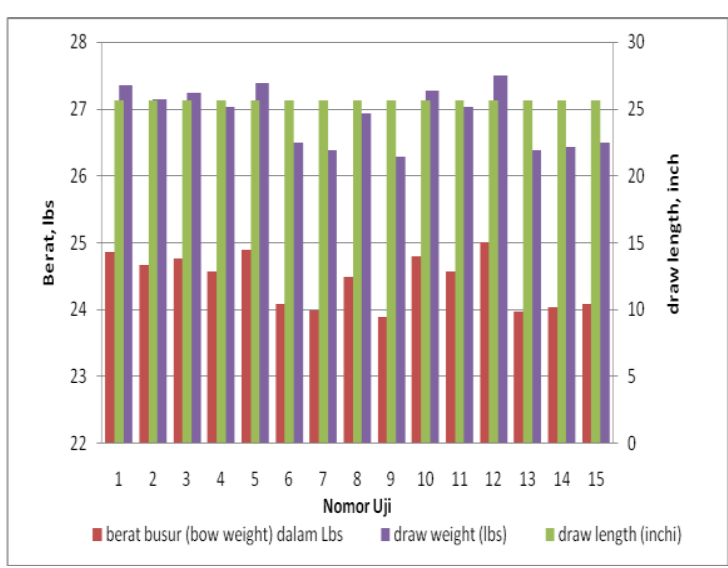

Gambar 7 Hasil perhitungan satu

Busur pertama dalam 15 kali uji coba berhasil didapat; bow weight antara 23,89 lbs hingga 25 lbs. Draw length menggunakan perhitungan draw length $=64$ inci $\div 2.5=25,6$ inci. Sementara draw weight mencapai 26,279 lbs hingga 27,5 lbs dengan metode hitung draw weight $=($ bow weight $\div 20 \times 2)+$ bow weight .

2. PVC masing-masing 27.56 inchi isian bambu seperti sumpit dan resin epoksi dengan tebal 1 $\mathrm{cm}$, riser dengan panjang 15,75 inchi, dan string 59,05 inchi.

Tabel 2 Perhitungan spesimen dua

\begin{tabular}{ccc}
\hline $\begin{array}{c}\text { Bow } \\
\text { Weight } \\
\text { (lbs) }\end{array}$ & $\begin{array}{c}\text { Draw } \\
\text { Length } \\
\text { (inchi) }\end{array}$ & $\begin{array}{c}\text { Draw Weight } \\
\text { (lbs) }\end{array}$ \\
\hline 28,88 & 26.6 & 31.768 \\
28,67 & 26.6 & 31.537 \\
29,76 & 26.6 & 32.736 \\
30,57 & 26.6 & 33.627
\end{tabular}




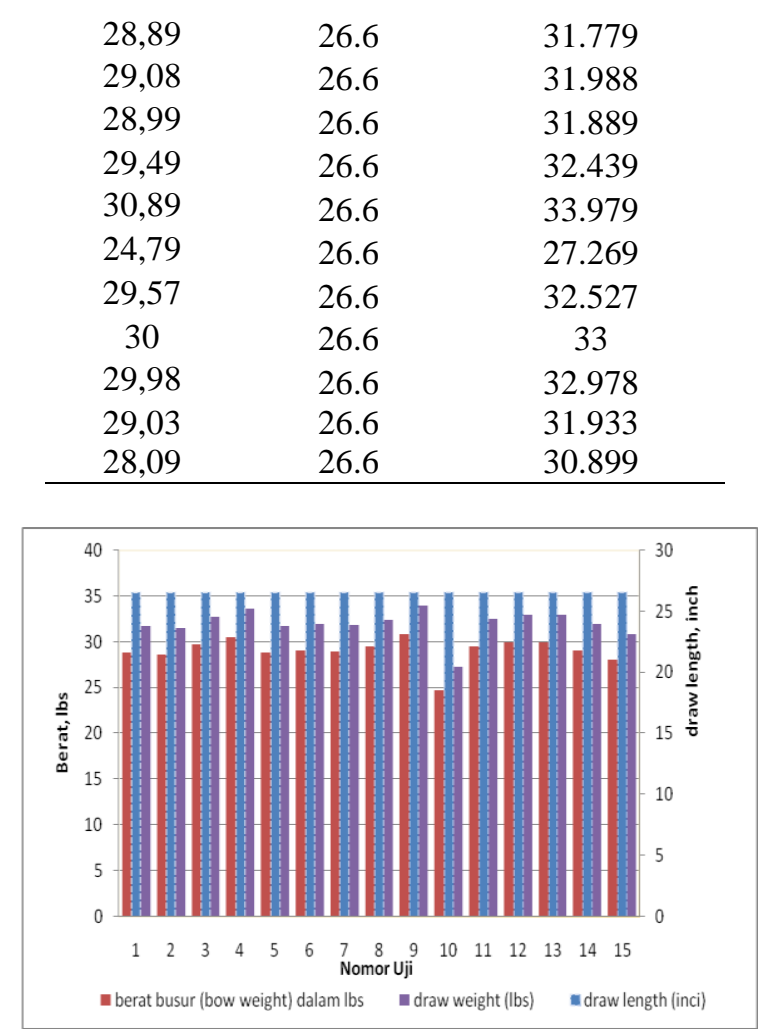

\section{Gambar 8 Hasil perhitungan spesimen dua}

Busur kedua dalam 15 kali uji coba berhasil didapat; bow weight 24,79 lbs hingga $30 \mathrm{lbs}$, draw length dengan perhitungan $=66,5 \div 2.5=$ 26,6 inci, draw weight mencapai $27,269 \mathrm{lbs}$ hingga 33 lbs dengan metode hitung draw weight $=($ bow weight $\div 20 \times 2)+$ bow weight .

3. PVC masing-masing 27.56 inchi isian resin epoksi dengan tebal $1 \mathrm{~cm}$, riser dengan panjang 15,75 inchi, dan string 59,05 inchi.

\begin{tabular}{ccc}
\multicolumn{3}{c}{ Tabel 3 Perhitungan spesimen tiga } \\
\hline $\begin{array}{c}\text { Bow } \\
\text { Weight } \\
\text { (lbs) }\end{array}$ & $\begin{array}{c}\text { Draw } \\
\text { Length } \\
\text { (inchi) }\end{array}$ & $\begin{array}{c}\text { Draw Weight } \\
\text { (lbs) }\end{array}$ \\
\hline 31,87 & 26.2 & 35.057 \\
31,67 & 26.2 & 34.837 \\
35,79 & 26.2 & 39.369 \\
34,58 & 26.2 & 38.038 \\
34,89 & 26.2 & 38.379 \\
34,08 & 26.2 & 37.488 \\
33,99 & 26.2 & 37.389 \\
34,49 & 26.2 & 37.939 \\
33,80 & 26.2 & 37.18 \\
34,89 & 26.2 & 38.379 \\
34,79 & 26.2 & 38.269 \\
35 & 26.2 & 38.5 \\
33,88 & 26.2 & 37.268 \\
34,43 & 26.2 & 37.873 \\
34,19 & 26.2 & 37.609 \\
\hline
\end{tabular}

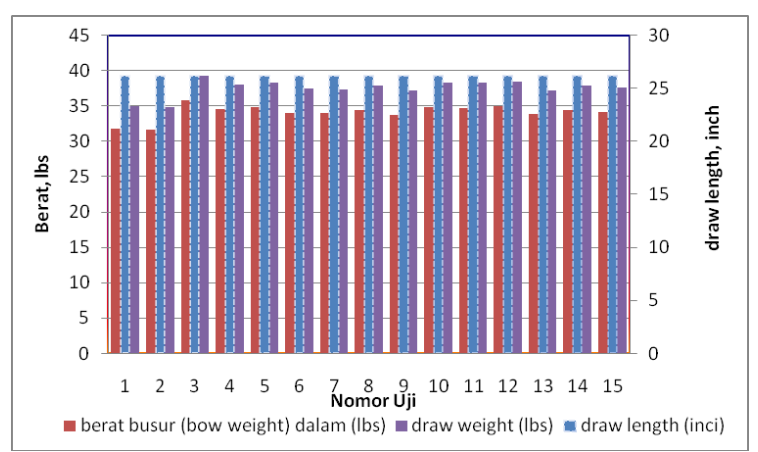

\section{Gambar 9 Hasil perhitungan spesimen tiga}

Busur ketiga dalam 15 kali uji coba berhasil didapat; bow weight 31,67 lbs hingga $35 \mathrm{lbs}$, draw length dengan perhitungan $=65,5$ $\div 2.5=26,2$ inci, draw weight mencapai 34,837 lbs hingga 38,5 lbs dengan metode hitung draw weight $=($ bow weight $\div 20 \times 2)+$ bow weight . 4. Pipa PVC tanpa isian, panjang riser dengan panjang 15,75 inchi, dan string 59,05 inchi.

\section{Tabel 4 Perhitungan spesimen empat}

\begin{tabular}{ccc}
\hline $\begin{array}{c}\text { Bow } \\
\text { (lbs) }\end{array}$ & $\begin{array}{c}\text { Draw } \\
\text { Length } \\
\text { (inchi) }\end{array}$ & $\begin{array}{c}\text { Draw Weight } \\
\text { (lbs) }\end{array}$ \\
\hline 31,87 & 26.2 & 35.057 \\
31,67 & 26.2 & 34.837 \\
35,79 & 26.2 & 39.369 \\
34,58 & 26.2 & 38.038 \\
34,89 & 26.2 & 38.379 \\
34,08 & 26.2 & 37.488 \\
33,99 & 26.2 & 37.389 \\
34,49 & 26.2 & 37.939 \\
33,80 & 26.2 & 37.18 \\
34,89 & 26.2 & 38.379 \\
34,79 & 26.2 & 38.269 \\
35 & 26.2 & 38.5 \\
33,88 & 26.2 & 37.268 \\
34,43 & 26.2 & 37.873 \\
34,19 & 26.2 & 37.609 \\
\hline
\end{tabular}

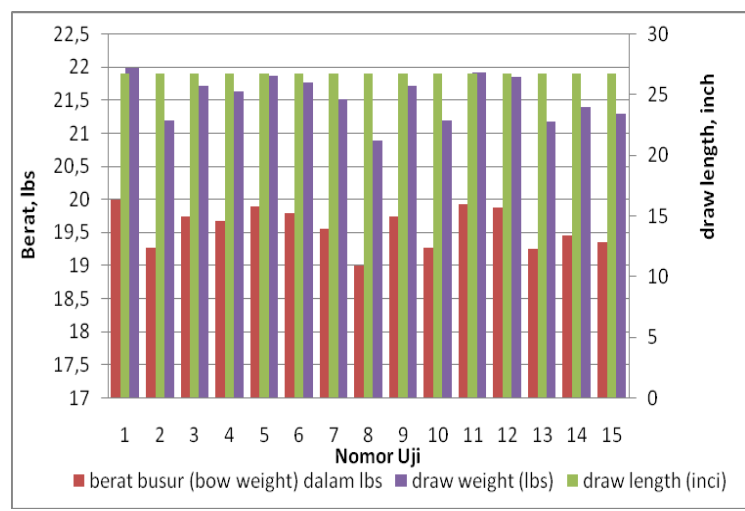

Gambar 10 Hasil perhitungan spesimen empat 
Busur keempat dalam 15 kali uji coba berhasil didapat; bow weight 19,25 lbs hingga $20 \mathrm{lbs}$, draw length dengan perhitungan $=67 \div 2.5=26,8$ inci, draw weight mencapai $21,175 \mathrm{lbs}$ hingga $22 \mathrm{lbs}$ dengan metode hitung draw weight $=($ bow weight $\div$ 20 X 2) + bow weight.

Hasil-hasil diatas ini mengacu pada archery manufacturers and merchants organization, yang meneruskan ASTM F-1544-96 dan F1752-96 dalam menemukan metode hitung.

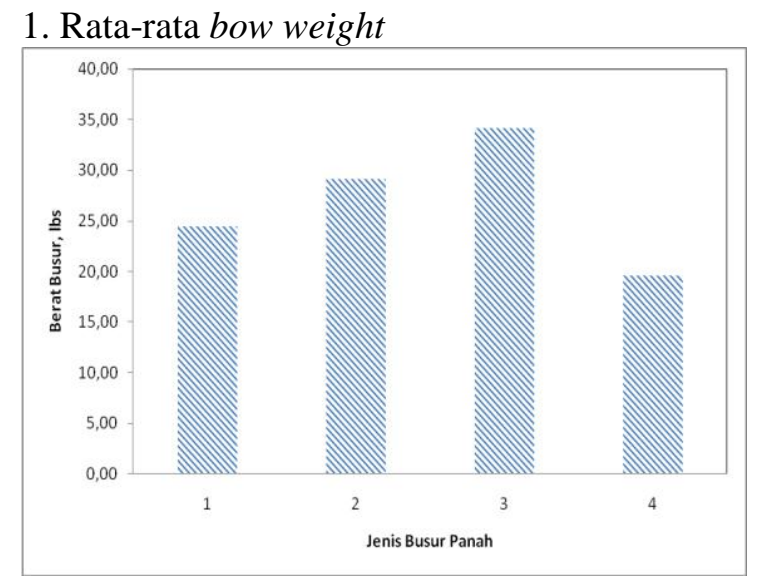

Gambar 11 Rata-rata berat busur

Rata-rata berat busur bervariasi 24,44 lbs, 29,11 lbs, 34,16 lbs, 19,59 lbs. Nilai yang mendekat untuk ukuran keempat spesimen antara 25-35 Ibs, dengan panjang string 59,01 dan panjang busur 62 inci ialah nomor dua.

2. Rata-rata draw weight

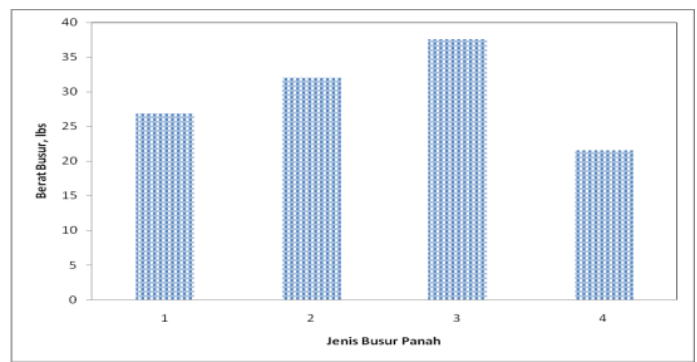

Gambar 12 Rata-rata draw weight

Rata-rata draw weight didapatkan dengan 15 uji coba per spesimen. Cara perhitungan ini menggunakan metode perhitungan; draw weight $=($ bow weight $\div 20 \times 2)+$ bow weight atau dengan cara perhitungan; draw weight = (bow weight $\div 20 \times 2.5$ ) - bow weight.
3. Rata-rata draw length

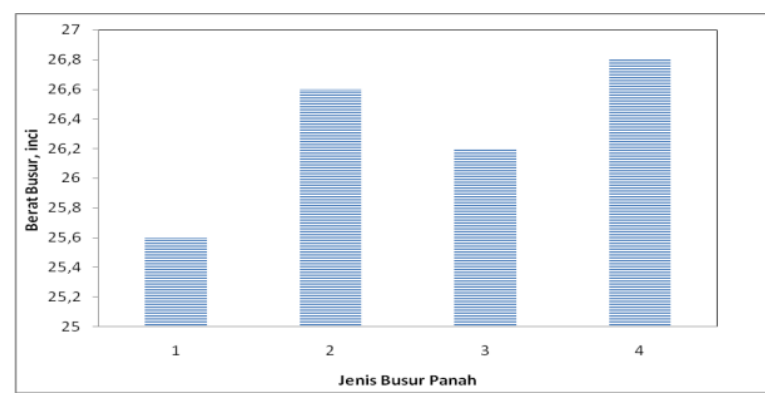

Gambar 13 Rata-rata draw length

Rata-rata draw length ini menggunakan metode ukur titik panjang tangan A ke panjang tangan $\mathrm{B}$, yang dibagi nilainya 2,5. Maka hal ini didapatkan angka 25,6 inci, 26,6 inci, 26,2 inci dan 26,8 inci.

\section{KESIMPULAN}

1. Berikut data bow weight, draw length, draw weight dari empat variasi busur panah:

a) Busur panah recurve dengan panjang limb menggunakan PVC 3/4 masing-masing 23.62 inci yang diisi bambu dengan tebal 1 $\mathrm{cm}$, panjang riser 15.75 inci, dan string 49,21 inci didapat; bow weight 24,44 lbs, draw length 25,6 inci dan draw weight 26,89 lbs.

b) Busur panah recurve dengan panjang limb menggunakan PVC 3/4 masing-masing 27,56 inci yang isian bambu seperti sumpit dan resin epoksi dengan tebal $1 \mathrm{~cm}$, riser dengan panjang 15,75 inci, dan string 59,05 inci didapat; bow weight 29,11 lbs, draw length 26,6 inci dan draw weight 32,02 lbs.

c) Busur panah recurve dengan panjang limb menggunakan PVC 3/4 masing-masing 27,56 inci yang isian resin epoksi dengan tebal $1 \mathrm{~cm}$, riser dengan panjang 15,75 inci, dan string 59,05 inci didapat; bow weight 34,16 lbs, draw length 26,6 inci dan draw weight $37,57 \mathrm{lbs}$

d) Busur panah recurve dengan panjang limb menggunakan PVC 3/4 masing-masing 27,56 inci, riser dengan 15,75 inci, dan string 59,05 inci didapat; bow weight 19,59 lbs, draw length 26,8 inci dan draw weight 21,54 lbs.

2. Hasil rancang bangun empat variasi busur panah diatas, busur panah ke dua, yang mendekati standard AMO manufacture, World Archery South Africa dan olimpiade. 


\section{Saran}

Uji coba ini jauh dari sempurna. Penggunaan bahan ini belum ada penelitian sebelumnya. Oleh karena itu masih mengikuti standard busur panah pada umumnya dalam menentukan standardisasi penelitian.

\section{DAFTAR PUSTAKA}

Johnson, Teresa, (2014). Archery Fundamentals, Human Kinetics, Inc, United States of America.

Karpowicz, A., (2008). Ottoman Turkish Bows: Manufacture And Design. Canada: Library and Archives Canada Cataloguing in Publication.

http://refhub.elsevier.com/S1359-

8368(14)00185-1/h0020

R. E. Smallman, R. J. Bishop, (1999), Modern Physical Metallurgy and Materials Engineering, Sixth Edition, ButterworthHeinemann, England.

World Archery South Africa, World Archery South Africa. 